\title{
APLIKASI DUA SEGITIGA SEBANGUN PADA STUDI VENUS TRANSIT DI MATAHARI TANGGAL 8 JUNI 2004 DARI BPD LAPAN WATUKOSEK
}

\author{
Nanang Widodo \\ Balai Pengamatan Dirgantara LAPAN Watukosek \\ Email: nang widodo@yahoo.com
}

\begin{abstract}
ABSTRAK
Transit planet Venus di cakram matahari (jari-jari $=696000 \mathrm{~km}$ ) merupakan peristiwa alam yang dapat dilihat secara berkala. Planet Venus merupakan planet kedua dalam sistem tata surya yang mempunyai orbit lebih dekat ke matahari $(=0,723$ Astronomical Unit) dibanding jarak bumi-matahari $(=$ 149.600.000 km = $1 \mathrm{AU}$ ). Sehingga pada suatu waktu tertentu ada peluang berada tepat di depan Bumi, saat menghadap matahari atau dikenal dengan transit Venus. Proses pengamatan fenomena transit Venus di cakram matahari tersebut dapat diimplimentasikan sebagai aplikasi dua segitiga sebangun, Dimana jari-jari planet Venus (jari-jari $=6051,8 \mathrm{~km}$ ) dinyatakan sebagai tinggi benda dan jari-jari tinggi bayangan Venus sebesar $20880 \mathrm{~km}(=3,65 \mathrm{~mm}$ pada cakram matahari). Dimana diameter matahari $1.392 .000 \mathrm{~km}$ (= $240 \mathrm{~mm}$ pada lembar sket). Dengan pengukuran jarak tempuh Venus transit $72,4 \mathrm{~mm}$ (419 $920 \mathrm{~km}$ di cakram matahari) terhadap waktu kontak pertama bayangan Venus pada jam 05.28 UT (12.28 WIB) di tepi timur hingga akhir transit pada 17.50 UT (14.50 WIB) diperoleh kecepatan bayangan Venus sebesar 49,286 km/detik.
\end{abstract}

Kata Kunci: orbit, segitiga sebangun,Venus transit.

\section{ABSTRACT}

Transit of the planet Venus in the Sun disk (radius $=696.000 \mathrm{~km}$ ) is a natural event that can be seen on a regularly. Venus is the second planet in the solar system have orbits closer to the sun $(=0.723$ Astronomical Units) compared to the Earth-Sun distance $(=149,600,000 \mathrm{~km}=1 \mathrm{AU})$. So that at any given time there are opportunities right in front of the Earth, while facing the sun or known by the Venus transit. The observation of the Venus transit on the Sun disc is implemented of application two congruent triangles, where the radius of Venus (6051.8 km) is expressed as object height and radius the shadow height of Venus is $20,880 \mathrm{~km}$ (= $3.65 \mathrm{~mm}$ in the Sun disk). Where the diameter of the Sun 1392 million $\mathrm{km}$ ( $=240 \mathrm{~mm}$ on the sketch). During a transit, Venus cover distance $72.4 \mathrm{~mm}$ or $419,920 \mathrm{~km}$ on the Sun disk. The first contact Venus shadow on the Sun Disk at 05:28 UT (12:28 pm) on the east limb until the end the transit at 17:50 UT (14:50 pm) obtained orbital speed of Venus shadow is $49.286 \mathrm{~km} / \mathrm{s}$.

Keywords: Orbit, triangle congruent, Venus transit

\section{PENDAHULUAN}

Henry Chamberlain Russel adalah pengamat pertama fenomena Venus transit tahun 1874. Dimana cahaya matahari dipantulkan oleh aerosol dan dibiaskan oleh atmosfer planet Venus, Glenn S (2004). Planet Venus disebut juga bintang pagi dan bintang sore oleh William, (1978). Hal terjadi karena planet Venus memantulkan cahaya dari matahari, selain itu posisi orbitnya berdekatan dengan Bumi.

Venus mengitari matahari dalam 224,701 hari Bumi $( \pm 0,615$ tahun Bumi). Karena dari perbedaan laju orbit Bumi dan Venus, maka Venus mengorbit 2,6 kali sedangkan Bumi mengorbit 1,6 kali, sebelum kedua planet segaris. Periode ini $(583,92$ hari Bumi) disebut Earth-
Venus synodic cycle. Peristiwa transit Venus ini serupa dengan fenomena Bulan melintas di depan matahari atau peristiwa gerhana matahari.

Tabel 1. Ukuran fisik Bumi dan Venus

\begin{tabular}{lll}
\hline kuran fisika & umi & enus \\
\hline iameter & $2.760 \mathrm{~km}$ & $2.100 \mathrm{~km}$ \\
irak rata-rata orbit & 49,6 & 08,2 \\
& ita $\mathrm{km}$ & ita km \\
eriode orbit & 65,25 & 24,7 \\
& ari & ari \\
udut inklinasi orbit & $\mathrm{J}$ &, $4^{\circ}$ \\
\hline
\end{tabular}

Peristiwa Venus akan transit kembali di tempat yang sama dalam waktu 243 tahun atau $121,5 \pm 8$ tahun di tempat berbeda, Nick A.F. (2004) 
Contoh foto planet Venus yang diambil dari proyek Magelan NASA, Nick . (2012)

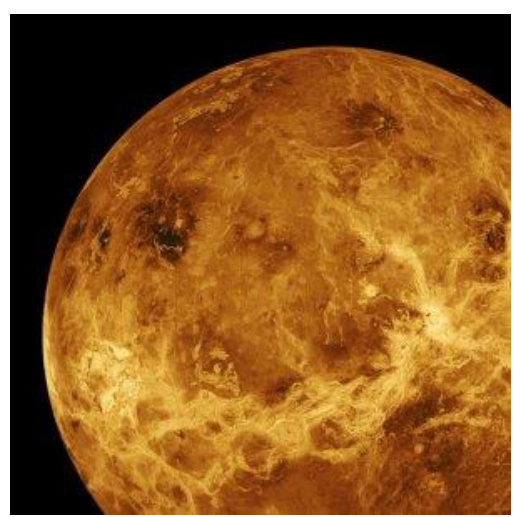

Gambar 1. Sebagian permukaan Venus, (Sumber: Venus Unveiled*Image Credit: NASA Magelan project).

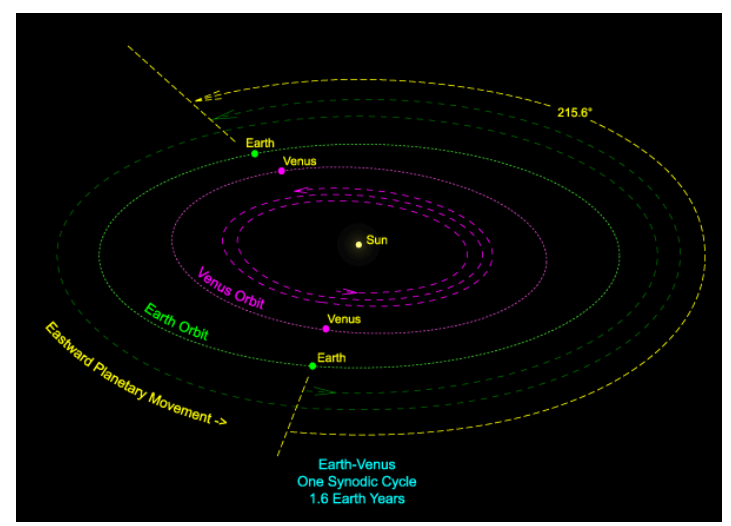

Gambar 2. Siklus-siklus sinodik

Berdasarkan perhitungan dari metoda ESO VT-2004 pada saat kontak pertaman transit Venus masuk cakram matahari, jarak Bumi matahari $149.596 .765 \mathrm{~km}$ (taraf kesalahan + $3534 \mathrm{~km}=0,0237 \%$ ) dengan solar parallax (II): 8,79440". Perbedaan waktu kontak transit Venus tergantung pada posisi bujur dari stasiun pengamat (http://www.isthe.com/chongo/tech/ astro/venus2004.html).

Fenomena transit Venus ini dapat digunakan untuk menjelaskan aplikasi teori dua segitiga sebangun. Konsep kesebangunan segitiga telah banyak dibahas dalam materi matematika geometri, Dalam menguji kesebangunan dua segitiga $\triangle \mathrm{ABC}$ dan $\Delta \mathrm{DEF}$ terdapat syarat-syarat antara lain:

1. Perbandingan panjang sisi-sisi yang bersesuaian pada kedua segitiga adalah sama besar

2. Dua pasang sudut yang bersesuaian adalah sama besar, atau dinyatakan dalam persamaan berikut:

$$
\frac{A B}{A D}=\frac{A C}{A E}=\frac{B C}{D E}
$$

Penjelasan persamaan (1) dapat digambarkan pada gambar 3

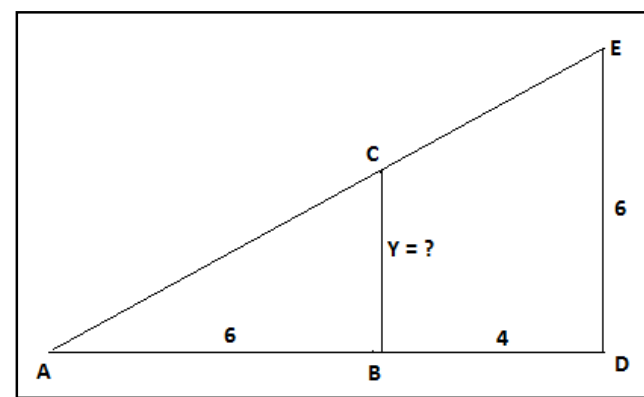

Gambar 3. Dua segitiga sebangun $\mathrm{ABC}$ dan ADE

Dengan asumsi indeks bias atmosfer Bumi dan atmosfer Venus diabaikan, maka dalam penelitian ini akan dilakukan perbandingan bayangan Venus dari persamaan (1) dan bayangan Venus (hasil sket) di cakram matahari.

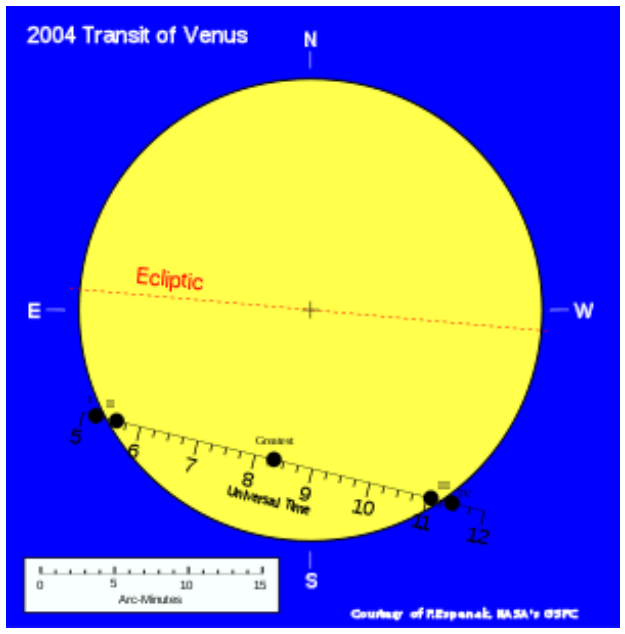

Gambar 4. Jalur Venus transit matahari (dari kiri ke kanan)

(Sumber: http://en.wikipedia.org/w/index.php? $\underline{\text { title}=\text { file2004 Venus Transit.svg\&p) }}$

\section{METODE PENELITIAN}

Dalam penelitian ini akan digunakan data hasil pengamatan transit Venus tanggal 8 Juni 2004 antara pukul 05.28 UT sampai 07.50 UT (12.28 - 14.50 WIB) dari Balai Pengamatan Dirgantara LAPAN Watukosek dengan teleskop sunspot.

Teleskop sunspot secara rutin digunakan untuk pengamatan aktivitas daerah aktif (sunspot = bintik matahari). Sehingga pada lembar sket tersebut tampak tiga grup sunspot di samping Venus transit.

Terdapat perbedaan arah Timur-Barat matahari pada gambar 4, disebabkan gambar 5 . adalah hasil proyeksi cahaya matahari pada bidang proyeksi dalam hal ini lembar sket adalah bayangan fotosfer matahari. 


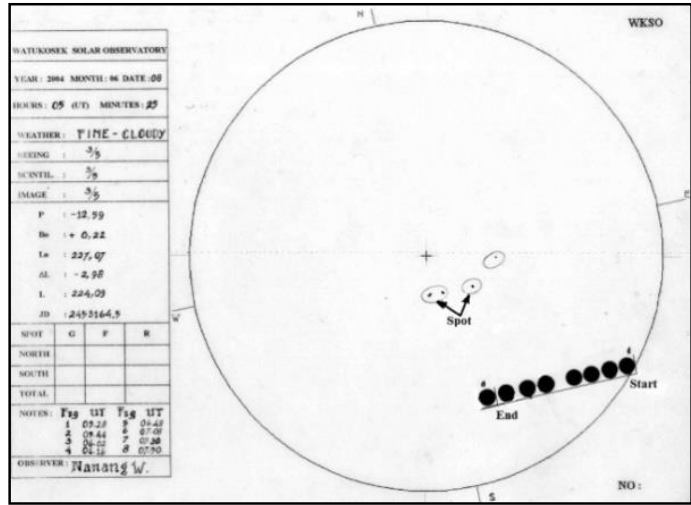

Gambar 5. Lintasan Venus di Matahari (dari kanan ke kiri), (Sumber: Pengamatan fotosfer matahari LAPAN BPD Watukosek).

Perbandingan diameter sket cakram matahari $(24 \mathrm{~cm})$ : diameter matahari (1.392.000 $\mathrm{km})=1: 5.800 .000 .000$. Jika terjadi kesalahan $1 \mathrm{~mm}$ dalam sket $=5800 \mathrm{~km}$ dalam ukuran sebenarnya di matahari.

Dalam penelitian ini akan dilakukan perbandingan beberapa besaran dari hasil pengamatan dan perhitungan, antara lain:

1. Perbandingan tinggi bayangan hasil perhitungan dengan hasil pengamatan (sket lintasan bayangan Venus).

2. Perbandingan kecepatan orbit (dalam teori) sesungguhnya dengan kecepatan bayangan Venus hasil pengamatan.

3. Mengetahui tingkat kesalahan pengukuran yang dipengaruhi oleh beberapa faktor fisis.

Segitiga ABC Segitiga ABC terdiri dari titik A adalah titik pengamatan di stasiun Bumi, B titik pusat Venus dan $\mathrm{C}$ adalah titik singgung permukaan planet Venus. Karena perbandingan jari-jari Venus terhadap jarak Bumi-Venus sangat kecil sebesar 1 : 6843, maka titik F dapat didekati dengan titik $\mathrm{C}$, seperti dalam perhitungan berikut.

Di mana jari-jari Venus $=6050 \mathrm{~km}$ dan jarak Bumi-Venus $=41.400 .000 \mathrm{~km}$, sehingga perbandingan jari-jari Venus terhadap jarak Bumi-Venus $=1: 6843$

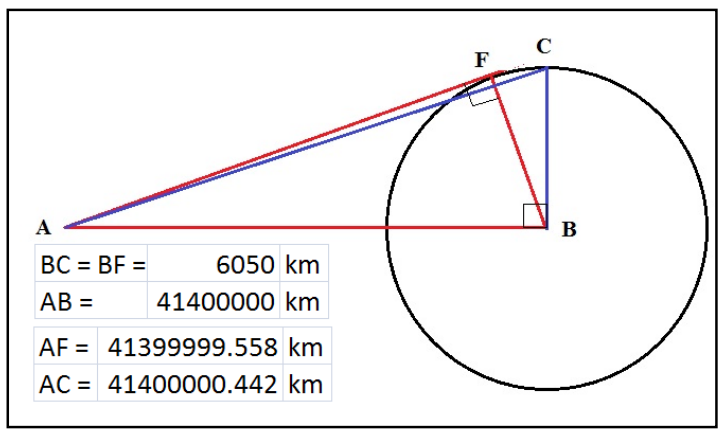

Gambar 6. Titik singgung F pada cakram Venus.

$$
\begin{aligned}
& A C=\sqrt{A B^{2}+B C^{2}} \\
& A F=\sqrt{A B^{2}-B F^{2}}
\end{aligned}
$$

di mana $B F=B C=$ jari-jari Venus. Sehingga jarak $\mathrm{B}-\mathrm{F}=41400000,442-41399999,558=1 \mathrm{~km}$, dapat diabaikan karena ketebalan atmosfer Venus. Asumsi ini digunakan untuk mencari besar bayangan Venus di cakram matahari.

\section{HASIL DAN PEMBAHASAN}

Segitiga ADE terdiri dari titik D adalah titik pusat bayangan planet Venus di cakram matahari dan $\mathrm{E}$ adalah titik terluar dari jari-jari bayangan.

Diameter bayangan Venus dari perhitungan persamaan (1), diperoleh

$$
\begin{aligned}
D E_{\text {hit }} & =B C\left(\frac{A D}{A B}\right) \\
& =6050 *\left(\frac{149600000}{41439200}\right)=43695 \mathrm{~km}
\end{aligned}
$$

Diameter bayangan Venus dalam sket, $\mathrm{DE}$ (sket) $=7,3 \mathrm{~mm}$

$\begin{aligned} D E_{\text {sket }}= & \left(\frac{\text { diameter bayangan Venus }(\mathrm{mm})}{\text { diameter Matahari }(\mathrm{mm})}\right) * \\ & \text { diameter Matahari }\end{aligned}$

$D E_{\text {sket }}=\left(\frac{7.3}{240}\right) * 1392000=42340 \mathrm{~km}$

Selisih diameter $=43695-42340$

$$
=1355 \mathrm{~km}
$$

atau dalam ukuran sket $= \pm 0,2337 \mathrm{~mm}$.

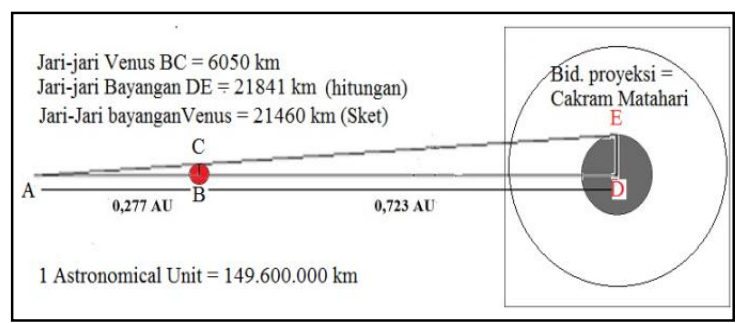

Gambar 7. Aplikasi $\Delta$ ABC dan $\triangle$ ADE pada transit Venus di cakram matahari.

Tabel 2.Posisi dan waktu pengamatan Venus transit 8 Juni 2004, LAPAN Watukosek

\begin{tabular}{ccc}
\hline o & $\begin{array}{c}\text { Waktu } \\
\text { )bserasi (UT) }\end{array}$ & $\begin{array}{c}\text { Titik tepi timur } \\
\text { Venus, mm }\end{array}$ \\
\hline$\vdots$ & 05.28 & 0 \\
$\vdots$ & 05.44 & 8,6 \\
$\vdots$ & 06.02 & 18,0 \\
06.16 & 26,8 \\
& 06.48 & 41,7 \\
& 07.08 & 51,5 \\
& 07.30 & 62,9 \\
\hline
\end{tabular}

Lintasan bayangan Venus transit di cakram matahari menempuh jarak $72,4 \mathrm{~mm}$ (419.920 km), dimana diameter matahari (sket) $=240 \mathrm{~mm}(1392000 \mathrm{~km})$. Lintasan bayangan venus sejauh $72.4 \mathrm{~mm}$ ditempuh dalam waktu 2 
jam 22 menit. Maka, kecepatan bayangan Venus = 49,286 km/dtk. Sedangkan kecepatan orbit Venus sebenarnya,

$$
\begin{aligned}
v & =\frac{\left(\frac{22}{7}\right)\left(R_{\text {pendek }}+R_{\text {panjang }}\right)}{224.7 \text { days }} \\
& =\frac{(0,5)(3.14286)(108.942 .109+107.476 .259)}{(224.7)(24)(3600)} \frac{\mathrm{km}}{\text { detik }} \\
& =35,03 \frac{\mathrm{km}}{\text { detik }}
\end{aligned}
$$

Selisih kecepatan orbit Venus dengan kecepatan bayangan saat transit sebesar 14,25 $\mathrm{km} / \mathrm{dtk} \simeq 0,0024 \mathrm{~mm} /$ detik (dalam sket).

Perbedaan kecepatan Venus transit disebabkan beberapa faktor antara lain;

1. Perekaman bayangan Venus dengan menggambar pada kertas sket (cakram Matahari), sehingga tingkat kesalahan masih besar.

2. Mengeliminasi pengaruh indek bias atmosfer Bumi dan Venus.

3. Faktor koreksi ukuran dalam lembar sket cakram matahari yaitu $1 \mathrm{~mm}$ (sket) $=5800$ $\mathrm{km}$ ukuran sebenarnya di cakram matahari.

4. Mengeliminasi kondisi pergerakan aerosol dan awan di atmosfer Bumi yang mengakibatkan bayangan semu batas tepi Venus.

Setelah kejadian Venus transit pada 8 Juni 2004 ini disusul dengan siklus pendek 8 tahunan, Venus kembali transit di cakram matahari pada tanggal 6 Juni 2012. Terdapat 3 jangka waktu siklus venus transit yaitu siklus pendek 8 tahun, siklus sedang 113,5 tahun dan 129,5 tahun. Pada masa yang akan datang, peristiwa Venus transit kembali terjadi pada 11 Desember 2117 (atau siklus 113,5 tahun) setelah peristiwa Venus transit tanggal 8 Juni 2004.

\section{PENUTUP}

Peristiwa transit Venus di cakram matahari ini dapat membantu pemahaman aplikasi dua segitiga sebangun yang diterapkan pada kejadian alam, dimana cakram matahari sebagai bidang proyeksi yang digunakan untuk merekam lintasan bayangan Venus selama transit. Jari-jari Venus sebesar $6050 \mathrm{~km}$ setelah diproyeksikan di cakram matahari diperoleh tinggi bayangan $21460 \mathrm{~km}$. Berdasarkan hitungan dua segitiga sebangun diperoleh tinggi bayangan Venus $21841 \mathrm{~km}$, sehingga terdapat koreksi $381 \mathrm{~km}( \pm 1,75 \%)$. Kecepatan bayangan Venus transit 49,286 km/detik relatif lebih cepat dibandingkan kecepatan orbit Venus sebenarnya yaitu 35,05 km/detik. Selisih kecepatan bayangan Venus transit sebesar 14,25 km/dtk atau $0,0024 \mathrm{~mm} / \mathrm{dtk}$ (dalam sket) disebabkan beberapa faktor fisis di alam dan ketepatan perekaman bayangan Venus di cakram matahari.

\section{DAFTAR PUSTAKA}

[1] Kesebangunan www.crayonpedia.org/mw,

segitiga, tanggal 11 Pebruari 2012,

[2] William J.K, (1978),"Exploration of the solar system", Macmillan Publising Co.Inc, Printed in The United States of America, Newyork

[3] Glenn Schneider (2004), "Transit of Venus 08 June 2004 trace white light ingress/egress imaging" Steward Observatory. University of Arizona.gschneider@as.arizona.edu http://nicmosis.as.arizona.edu:8000. How far is the Sun? Transit of Venus 8 June 2004 observations, diunduh tanggal 20 Nopember 2012.

http://www.isthe.com/chongo/tech/astro/ venus2004.html

[4] Nick Anthony Fiorenza (2012), "The Venus Transits the pentagonal Cycle of Venus", Cycles of the Heart June 8, 2004 and June 56, 2012.

[5] Transit of Venus, 2004, diunduh tanggal 24 Oktober 2012 http://en.wikipedia.org/w/index.php?title= file2004 Venus Transit.svg\&p

[6] Synodic cycles and planetary retrogrades to learn more about synodic cycles and synodic astrology, WWW.lunarplanner.com/HCpages/Venus.h $\underline{\text { tml }}$, diunduh 2 Pebruari 2013

[7] Jack A Stone and Jay H. Zimmerman "Index of Refraction Air", diunduh 2 Desember 2012,

http://emtodbox.nist.gov/wavelength/doc umentation.nsp\#indexof 